\title{
DEVELOPING FREE-FLOW SPEED MODELS FOR URBAN ROADS UNDER HETEROGENEOUS TRAFFIC CONDITIONS
}

\author{
Srijith Balakrishnan ${ }^{1}$, Ramaswamy Sivanandan ${ }^{2}$ \\ ${ }^{1}$ Department of Civil, Architectural and Environmental Engineering, The University of Texas at Austin, USA \\ ${ }^{2}$ Department of Civil Engineering, Indian Institute of Technology Madras, India
}

Received 6 May 2017; accepted 9 October 2017

\begin{abstract}
Free-flow speed (FFS) is the desired speed that drivers choose when no (or very less number of) vehicles are present in the road segment. FFS is an important parameter of traffic flow that decides the level of service and capacity aspects of various types of highway facilities. Estimation of FFS is extremely time consuming and requires extensive human resource and capital. Hence, a FFS model can be a solution to bring down the above difficulties while ensuring satisfactory prediction of FFS. In countries like India, a widely used method of estimating FFS is to collect vehicle speeds from field during low volume hours. However, this method requires significant amount of time, human resource and capital for studies on large road networks. Hence, it is essential to develop models to predict free-flow speeds. It is important that models are capable of capturing the free-flow speed variations due to local road factors. Majority of the existing free-flow speed models are developed under homogeneous traffic conditions, in which passenger cars dominate the vehicle composition. However, the traffic condition in emerging economies like India is heterogeneous in nature characterized by the presence of multiple vehicle categories with varying physical and dynamic characteristics. The present paper attempts to investigate the influence of different road factors on FFS on urban roads of Chennai, India. The paper also tries to capture the FFS variations across different classes of vehicles and develop FFS prediction models. The typical Indian traffic comprises significant percentage of slow moving vehicles like three-wheelers as well as fast moving sedans and SUVs. Composition of traffic and corresponding proportions of different classes are important factors that differentiate heterogeneous and homogeneous traffic. The presented models could explore the driver speed behavior with respect to the aforementioned factors into consideration.
\end{abstract}

Keywords: Free-flow speed; heterogeneous traffic; divided urban roads; vehicle speed factors.

\section{Introduction}

Free-flow speed (FFS) is an important parameter in traffic and planning studies and have extensive applications in a wide range of transportation engineering problems. The term FFS is defined as "the average speed of vehicles under low volume conditions, when the drivers tend to drive at their desired speed without being affected by control delay" (Transportation Research Board, 2010). FFS of a vehicle is not influenced by front, rear or lateral vehicles, or weather conditions. Theoretically, FFS is the speed of the vehicles when both density and flowrate in the traffic stream are zero.

${ }^{1}$ Corresponding author: srijith@utexas.edu 
FFS finds its application in a wide spectrum of transportation engineering studies, ranging from capacity estimation to air quality management. Free-flow condition is regarded as a benchmark to compare and quantify capacity and congestion (Anjaneyulu and Nagaraj 2009; Bang et al., 1995), travel time delays (Cambridge Sytematics et al., 2008; Schrank et al., 2012), air quality and fuel consumption (Odoki and Kerali, 2000; Ross, 1994) under different traffic conditions. In addition, FFS is used to determine posted speed limits and their efficiency (Fazio et al., 2014; Moses and Mtoi, 2013; Sun, 2010), level of service (Transportation Research Board, 2010), etc. FFS is also used to ascertain driver behaviour on given facility, and evaluate interactions between vehicles and road conditions.

Estimation of FFS is critical in any traffic study, because it varies significantly across road facilities. This can be attributed to the factors affecting FFS and their extent of influence in each road category. For e.g., FFS on interrupted facilities is influenced by driver, road and traffic control characteristics. The road characteristics include carriageway width, geometric design, side clearance, type of landuse, type of roadway, etc. Traffic control characteristics include signalized and unsignalized intersections, speed management measures, etc. Along with the above factors, FFS is also influenced by environmental factors such as rain, snow and poor visibility. However, in the case of uninterrupted facilities such as rural freeways and expressways, the extent of influence of traffic control measures would be comparatively lower.

The most extensive studies on FFS and its influencing factors are carried out by Transportation Research Board (TRB) in the United States. The effects of various factors affecting FFS are quantified and FFS prediction models for freeways, multilane highways and urban arterials are presented in the Highway Capacity Manual. The models suggest that FFS on U.S. roads are largely determined by lane width, lateral clearance, median type, ramp density and intensity of access points. However, in case of urban arterials, an important influencing factor is the speed limit.

There are several other studies that developed FFS models for more localized road networks. (Yagar and Van Aerde, 1983) studied the influence of road factors on FFS on two-lane highways in Ontario, Canada and found that speed limit and upstream land use are the most influencing factors. (Dixon et al., 1999) conducted a study in Georgia, United States to investigate the consequences of a legislative amendment to raise speed limits on vehicle speeds. The researchers developed models using speed limit, 85th percentile speed, access density, heavy vehicle percentage composition and vertical grade as influencing factors to predict FFS. (Kyte et al., 2000) studied the influence of a range of weather-related factors on vehicle FFS. The researchers constructed three regression models to quantify the effect of precipitation, visibility, road surface condition and wind speeds on FFS. Figueroa and Tarko (2005) found that FFS in rural highways is also influenced by geometric design, in addition to the existing roadway characteristics. The authors developed two Ordinary Least Square-Panel Data (OLS-PD) models to evaluate FFS on tangent and curved highway elements. Himes et al., (2013) conducted studies on the operating speeds on different lanes of four-lane limited access rural highways in North Carolina and Pennsylvania, U.S. 
Statistical analyses showed that factors such as posted speed limits, access density, horizontal curve, intensity of signalized intersection, etc. influence average lane speed and its deviation. Saifizul et al., (2011) analyzed FFS of various vehicle categories on Malaysian multi-lane highways to identify the relationship between FFS and gross vehicle weight (GVW). The two-way Analysis of Variance (ANOVA) results confirmed that GVW and vehicle class are dependent, and thus influence FFS. De Luca et al. (2012) investigated several geometric factors such as vertical grade, horizontal curvature, tortuousness and section width and their relationship with FFS. The study found that horizontal curvature, vertical grade and tortuousness influence FFS. In a recent study, Moses and Mtoi (2013) evaluated the FFS on urban arterials in Tallahassee, Florida. Three linear regression models (principal arterial model, minor arterial model and aggregate model) for FFS were constructed with influencing factors such as proportion of kerb, proportion of median, and speed limit. The efficacy of developed models was compared with that of existing FFS models developed using (Highway Capacity Manual, 2010) and Florida Department of Transportation (FDOT) methods.

The above studies, however, are based on homogeneous traffic where the vehicle composition is predominantly passenger cars, and through-vehicle movements are restricted by lane discipline. On the contrary, heterogeneous traffic, as prevalent in India, is characterized by the presence of several vehicle classes varying in size, shape, etc., and are unrestricted for lateral displacements during through movement. This makes heterogeneous traffic challenging and unpredictable. Hence, the direct application of Highway Capacity Manual models and similar FFS models in countries like India may not be appropriate. Moreover, the limited traffic law enforcement along with failure of drivers to comply with traffic regulations in countries like India make the field reality complex.

There have been a few notable studies on FFS under heterogeneous traffic too. As part of developing the Indonesian Highway Capacity Manual, Bang (1995) studied the influence of lateral impedance on FFS on urban and rural roads in Indonesia. A similar study by the same researcher and his team evaluated the effect of road class and lane width of the same classes of roads in Indonesia (Bang et al., 1995). (Tseng et al., 2005) developed FFS models for urban arterial roads in Taiwan. The models used intersection spacing, arterial road class, median type and vehicle category (twowheelers and small vehicles) as influencing factors. (Ma et al., 2010) investigated the effect of lane width on FFS of urban roads of Hangzhou, China and identified the optimum lane width to minimize speed variation and improve safety. In an extensive study on urban roads in Nigeria, (Yusuf, 2010) quantified the influence of vehiclespecific characteristics (age of drivers, vehicle occupancy, vehicle age, etc.) and site-specific features (pavement surface conditions, geometric factors, etc.) on FFS of various vehicle types.

In India, the research on FFS is in its nascent stage. The most important studies include those by (Kadiyali et al., 1983; Madhu, 2004). These studies, however, are conducted on rural multi-lane highways. Recently, (Rao and Rao, 2015) presented a FFS model for urban roads in New Delhi with flow rate, number of friction points, major 
intersections, and number of flyovers, access points and length of sections as independent variables. However, the heterogeneity of vehicles is not captured in the model. In order to study the effect of factors such as vehicle subclass, carriageway width, link length, landuse, presence of kerb, and lane position on FFS, (Balakrishnan and Sivanandan, 2015) developed disaggregate models for divided urban roads in Chennai. However, the models assumed that the effect of all road factors is uniform across vehicle types, which warrants further scrutiny.

Due to lack of prediction models, most of the planning and traffic studies in India estimate FFS from field manually. An alternative approach is to assume FFS for studies or adopt speed limit as FFS. This may give meaningful results in non-urban roads, as speed limits are comparatively higher and comply with design speeds. However, on urban roads, this may not be accurate, as the speed limits are generally kept lower for safety reasons. Hence, majority of vehicles tend to prefer a speed higher than the existing speed limits.

The manual estimation of FFS on urban roads in India is extremely difficult due to the presence of high volume of traffic and intense roadside activity throughout the daytime. In addition, manual estimation of FFS is extremely time consuming and requires extensive human resource and capital. Building FFS models using relevant influencing factors could be a solution to bring down the aforementioned difficulties while ensuring satisfactory prediction of FFS. It is also important to study the influence of various factors on FFS and their extent of influence on different classes of vehicles in heterogeneous traffic. The present study is an attempt to model FFS on urban divided roads in Chennai, India, by incorporating relevant road factors and examine the effect of these on FFS of different vehicle classes predominant in Indian traffic. The study also shows that class-wise models are capable of capturing FFS patterns in heterogeneous traffic in a better way compared to the overall FFS models.

\section{Data Collection and Extraction}

\subsection{Description of Study Area}

The present study was focused on the urban roads in Chennai, India. The road network in the city has a radial and ring pattern, and the total length of the network is approximately $2780 \mathrm{~km}$. For the present study, only divided arterial and sub-arterial roads were considered. A total number of twenty-four study sections were selected from different locations of urban and suburban areas of Chennai. The following conditions were adopted during the selection of study segments:

- Divided arterial roads and subarterial roads were chosen for the study;

- Mid-block segments were selected to minimize the effect of signalized intersections;

- Straight segments devoid of curves were chosen;

- The study segments were devoid of temporary or permanent speed management devices such as barricades and speed breakers. Drivers tend to reduce speeds which could result in incorrect FFS estimates;

- Those segments with bus stops within them were avoided. Reported FFS of buses may be lower than the actual value if the buses stop within the study segments; 
- All study segments were located on flat terrain;

- All study segments were of good pavement condition.

Reconnaissance surveys and site investigations were conducted prior to the selection of study segments. During the site investigation, due consideration was given to select segments with varying road factors (carriageway width, link length, side clearance, landuse, roadside features, etc). Finally, a representative sample of twenty-four divided urban road segments was identified for data collection.

\subsection{Data Collection}

\subsubsection{Speed Factors Considered in the Study}

The foremost objective of the study was to ascertain the effect of various factors affecting FFS on urban roads under heterogeneous traffic conditions and develop prediction models. The scope of present study is limited to site and vehicle factors. The site factors considered for the study include carriageway width (cway), link length (link), side clearance (side), number of access points (access), presence of kerb (kerb), road class, landuse and area type. It has been already mentioned that only two classes of roads were considered, namely arterial (art) and subarterial (subart) roads. Similarly, four levels of landuse types - commercial (land.com), residential (land.res), institutional (land.inst) and open area (land.open) - were considered. The segments were chosen from two different area types- urban ( $u r b$ ) and suburban (suburb) areas. The vehicle factors considered for the study include vehicle class and subclass. The factors vehicle class and subclass were considered to capture the heterogeneity in traffic. Six vehicle classes (two-wheelers, three-wheelers, passenger cars, light commercial vehicles, buses and trucks) consisting fourteen subclasses were studied. The vehicle classes and subclasses were chosen based on the size and shape of the vehicles.

\subsubsection{Experimental Setup and Data Collection}

The details related to site factors in each study location were measured and recorded during site investigation. Linear measurements were taken using a rodometer and a laser distance meter. The other site factors were recorded using a camcorder and the required site details were extracted later. The details of site factors are enlisted in Table 1.

After collecting the site details and finalizing the segments, video data collection was carried out. Video data collection was intended to determine the FFS of individual vehicles on selected study segments. The other vehicle details such as vehicle class and subclass were also captured. Videography technique involving two camcorder-tripod pairs was used for the purpose. Camcorders mounted on tripods were used to record vehicle movements at the ends of each study segment. The camcorders were placed at an elevation of $1.2 \mathrm{~m}$ to $1.6 \mathrm{~m}$ above the ground level and $3 \mathrm{~m}$ to $7 \mathrm{~m}$ away from the pavement edge. The line of sight of the camcorders were maintained at $90^{\circ}$ to the direction of traffic movement. 


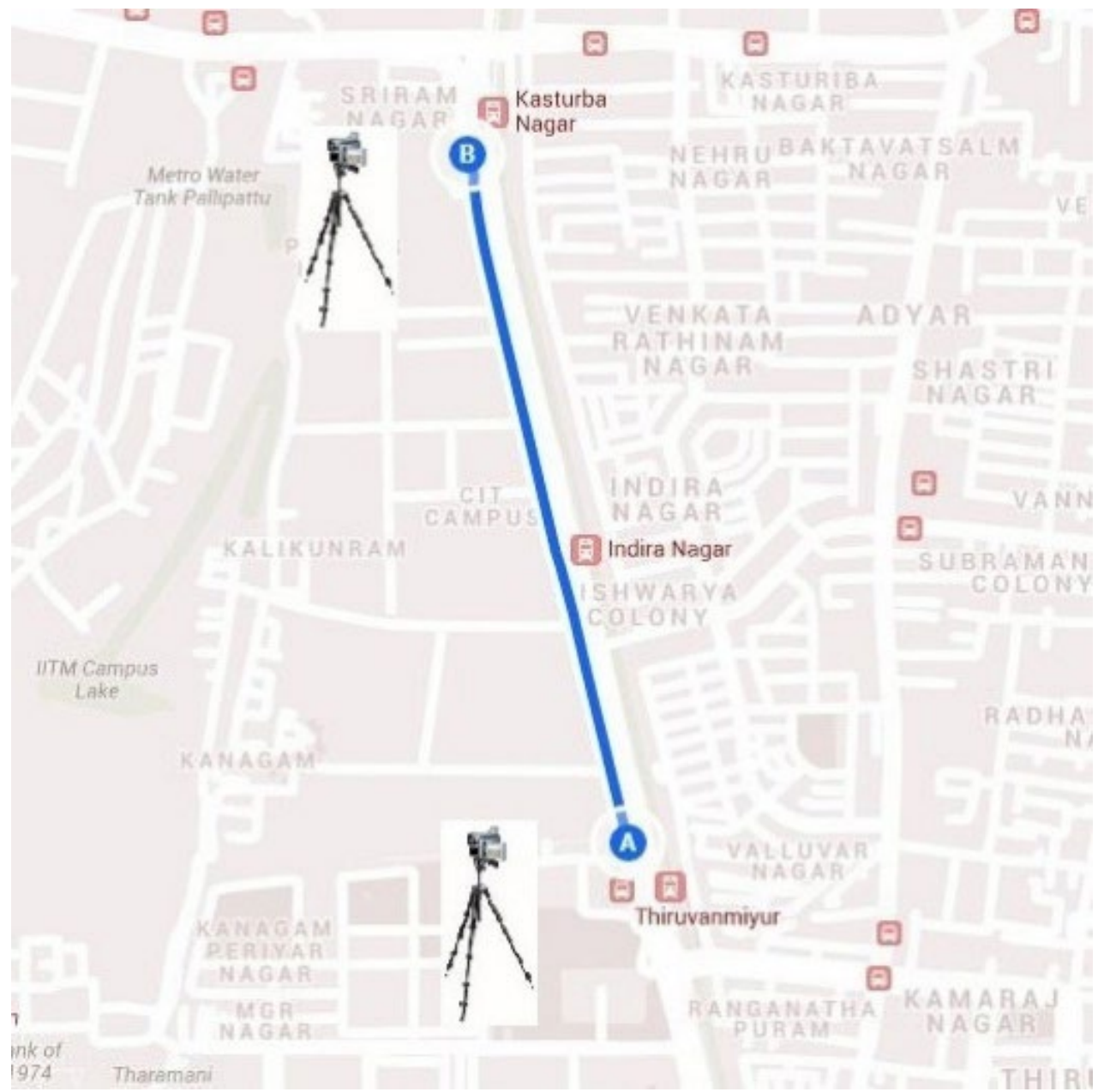

Fig. 1.

Camcorder Setup for Video Data Collection

To ensure free-flow conditions, video data collection was conducted between $3.30 \mathrm{am}$ and $7.30 \mathrm{am}$, depending on the traffic flow rate on various study segments. Traffic flow-rate varied from $300 \mathrm{PCU} / \mathrm{h}$ to $1000 \mathrm{PCU} / \mathrm{h}$ during this time period. The camcorders (A and B as shown in Fig. 1) were time synchronized for travel time calculations. Around 1.5 hours of video data was recorded in each study location. In order to maintain free-flow conditions, video data collection under poor lighting conditions and inclement weather was avoided. Poor lighting and inclement weather affect visibility adversely, resulting in reduced vehicle speeds. 
Table 1

Site Details of Study Sections

\begin{tabular}{|c|c|c|c|c|c|c|c|c|c|}
\hline Site ID & $\begin{array}{l}\text { Link } \\
\text { length }\end{array}$ & $\begin{array}{l}\text { Carriage- } \\
\text { way width }\end{array}$ & $\begin{array}{l}\text { Side } \\
\text { clearance }\end{array}$ & $\begin{array}{l}\text { Segment } \\
\text { length }\end{array}$ & $\begin{array}{l}\text { No. of } \\
\text { lanes }\end{array}$ & $\begin{array}{l}\text { Road } \\
\text { class }\end{array}$ & $\begin{array}{l}\text { Area } \\
\text { type }\end{array}$ & Landuse & Kerb \\
\hline & $(m)$ & $(m)$ & $(m)$ & $(m)$ & (nos.) & & & & \\
\hline 1 & 890 & 12.20 & 8.00 & 650 & 6 & art & $u r b$ & land.com & yes \\
\hline 2 & 1730 & 10.65 & 18.40 & 455 & 6 & art & suburb & land.com & no \\
\hline 3 & 1470 & 7.60 & 2.50 & 700 & 4 & subart & $u r b$ & land.res & yes \\
\hline 4 & 1390 & 7.60 & 4.10 & 756 & 4 & art & $u r b$ & land.com & yes \\
\hline 5 & 640 & 7.50 & 2.40 & 424 & 4 & art & $u r b$ & land.com & no \\
\hline 6 & 1920 & 9.70 & 2.60 & 610 & 4 & art & $u r b$ & land.inst & yes \\
\hline 7 & 1990 & 8.50 & 3.00 & 437 & 4 & art & $u r b$ & land.inst & no \\
\hline 8 & 2610 & 8.70 & 20.00 & 1100 & 4 & art & suburb & land.open & no \\
\hline 9 & 1330 & 7.90 & 5.00 & 1100 & 4 & art & suburb & land.com & no \\
\hline 10 & 1020 & 10.95 & 3.00 & 670 & 6 & art & $u r b$ & land.res & yes \\
\hline 11 & 760 & 8.60 & 2.25 & 525 & 4 & art & $u r b$ & land.com & no \\
\hline 12 & 1100 & 6.80 & 6.80 & 450 & 4 & subart & $u r b$ & land.com & no \\
\hline 13 & 1740 & 6.45 & 6.22 & 463 & 4 & subart & $u r b$ & land.inst & yes \\
\hline 14 & 1740 & 7.50 & 6.90 & 463 & 4 & subart & $u r b$ & land.inst & no \\
\hline 15 & 1240 & 8.90 & 1.95 & 940 & 4 & art & $u r b$ & land.inst & yes \\
\hline 16 & 910 & 7.20 & 20.00 & 910 & 4 & art & suburb & land.open & no \\
\hline 17 & 800 & 6.90 & 2.50 & 570 & 4 & subart & $u r b$ & land.res & yes \\
\hline 18 & 1050 & 9.30 & 6.45 & 599 & 6 & art & $u r b$ & land.inst & yes \\
\hline 19 & 980 & 10.42 & 2.00 & 374 & 6 & art & $u r b$ & land.com & no \\
\hline 20 & 1580 & 6.70 & 2.10 & 630 & 4 & subart & $u r b$ & land.res & yes \\
\hline 21 & 1870 & 10.30 & 7.00 & 707 & 6 & art & $u r b$ & land.inst & no \\
\hline 22 & 1980 & 9.40 & 11.30 & 1650 & 6 & art & $u r b$ & land.inst & yes \\
\hline 23 & 1950 & 9.40 & 10.00 & 600 & 6 & art & $u r b$ & land.com & yes \\
\hline 24 & 550 & 8.90 & 5.20 & 370 & 6 & subart & $u r b$ & land.res & yes \\
\hline
\end{tabular}

\subsection{Data Extraction}

After completing data collection from all selected study segments, the next step was to extract vehicle-related data relevant for the study from the video data. First, the vehiclerelated data (vehicle class, vehicle subclass, lane number and starting point time stamp of individual vehicles) were manually extracted from the starting point video (Video 1 ), and recorded. Six vehicle categories were considered for the study - two-wheelers $(2 \mathrm{~W})$, three-wheelers $(3 \mathrm{~W})$, passenger cars (Car), light commercial vehicles (LCV), buses (Bus) and trucks (Truck). Each of the vehicle classes were further classified into subclasses as well, for detailed analysis.
Once the extraction of vehicle-related data from Video I was completed, the end point video (Video II) was analysed. The vehicles identified in Video I were matched in Video II and corresponding time stamps were noted. The free-flow travel time of a vehicle was obtained as the difference in the time stamps in Video I and Video II. Finally, FFS was computed as the ratio of length of segment to the travel time under free-flow condition.

21,304 vehicles were analysed during the extraction phase of the study. There were several missing data, primarily due to the vehicles which diverted to access roads present within the study stretches. After removing the missing data, a final sample 
consisting of 17,799 vehicles was obtained. The dataset collected for the study is one of the biggest samples used for FFS studies in India. Since the extraction of data was done manually, significant amount of time was spent for this stage of the study. On an average, a 90-minute video data from a study segment required almost two weeks for extraction and tabulation. The video data collection and extraction phase of the study was carried out between January 2013 and March 2015.

\section{Data Analysis}

Once the estimation of individual FFS was completed, the speeds were analyzed and the effects of various site and vehicle factors were evaluated. Multiple regression analysis was adopted to develop FFS prediction models. The analysis results are presented in the following subsections.

\subsection{Analysis of Class-Wise Individual Free-Flow Speeds}

The vehicles studied were categorized under 6 classes and 14 subclasses. The classification was based on the vehicle characteristics and size. The heterogeneity of vehicles is assumed to be one of the major factors governing FFS on Indian roads. The descriptive statistics of different classes and subclasses of vehicles are presented in Table 2.

Table 2

Descriptive Statistics: FFS of Different Vehicle Classes and Subclasses

\begin{tabular}{|c|c|c|c|c|c|c|c|}
\hline \multirow{2}{*}{ Class } & \multirow{2}{*}{ Subclass } & \multirow{2}{*}{$\begin{array}{l}\text { Sample } \\
\text { Size }\end{array}$} & \multicolumn{5}{|c|}{ Free-flow speed $(\mathrm{km} / \mathrm{h})$} \\
\hline & & & Minimum & Median & Mean & Maximum & Std. Dev. \\
\hline \multirow{4}{*}{$2 \mathrm{~W}$} & Overall & 6353 & 16.03 & 46.27 & 47.50 & 125.00 & 12.39 \\
\hline & Bike & 4901 & 16.03 & 47.71 & 49.19 & 125.00 & 12.43 \\
\hline & Scooter & 1110 & 18.14 & 42.35 & 43.60 & 83.69 & 10.44 \\
\hline & Moped & 342 & 18.94 & 34.92 & 36.00 & 68.28 & 7.98 \\
\hline \multirow{3}{*}{$3 \mathrm{~W}$} & Overall & 1496 & 18.00 & 38.99 & 39.73 & 84.80 & 9.07 \\
\hline & Goods & 72 & 22.89 & 38.33 & 38.14 & 58.81 & 6.78 \\
\hline & Passenger & 1424 & 18.00 & 39.00 & 39.81 & 84.80 & 9.16 \\
\hline \multirow{4}{*}{ Car } & Overall & 5848 & 16.53 & 60.43 & 61.27 & 137.70 & 15.68 \\
\hline & Hatchback & 2848 & 16.53 & 59.90 & 60.61 & 119.70 & 15.52 \\
\hline & Sedan & 1272 & 17.23 & 60.65 & 62.00 & 137.70 & 15.76 \\
\hline & SUV & 1728 & 17.61 & 60.60 & 61.82 & 117.10 & 15.85 \\
\hline \multirow{3}{*}{$\mathrm{LCV}$} & Overall & 1759 & 15.88 & 52.11 & 53.31 & 104.90 & 13.87 \\
\hline & Goods & 1044 & 15.88 & 49.91 & 50.49 & 101.70 & 11.89 \\
\hline & Passenger & 715 & 17.61 & 56.48 & 57.43 & 104.90 & 15.45 \\
\hline \multirow{4}{*}{ Bus } & Overall & 1480 & 17.68 & 46.16 & 46.81 & 121.20 & 11.58 \\
\hline & MTC & 786 & 21.37 & 42.17 & 42.33 & 76.15 & 9.86 \\
\hline & Interstate & 484 & 24.51 & 52.43 & 53.28 & 97.50 & 10.67 \\
\hline & Institutional & 210 & 17.68 & 47.57 & 48.63 & 121.20 & 12.04 \\
\hline \multirow{2}{*}{ Truck } & Overall & 863 & 18.95 & 44.27 & 45.88 & 97.49 & 10.42 \\
\hline & Truck & 863 & 18.95 & 44.27 & 45.88 & 97.50 & 10.42 \\
\hline \multicolumn{2}{|c|}{ Whole Sample } & 17799 & 15.88 & 49.78 & 51.81 & 137.70 & 15.17 \\
\hline
\end{tabular}


The results show that the average FFS of cars is the highest $(61.27 \mathrm{~km} / \mathrm{h})$ and that of threewheelers is the lowest $(39.73 \mathrm{~km} / \mathrm{h})$. The FFS of other classes of vehicles were also found to be different, reiterating that the speed difference among vehicle groups is an important aspect in heterogeneous traffic. Like the class-wise speed difference, there was significant speed difference across subclasses too. It was found that among two-wheelers, motor bikes had the highest speed and mopeds were the slowest. In the case of three-wheelers, the difference in FFS was negligible between the two subclasses. Similarly, the three subclasses of passenger cars (sedan, hatchback and SUV) had similar FFS distributions. Among LCVs, passenger carriers were faster compared to goods carriers. Similarly, the interstate buses had higher FFS compared to institutional and MTC buses (city buses).

\subsection{Estimation of Free-Flow Speeds}

Equation 1 gives the formulae for calculating overall and class-wise FFS of vehicles. Twominute FFS is modelled in the present study. The individual FFS data were aggregated for every two minutes based on the entry time.

$\mathrm{FFS}_{2 \text { min }}=\frac{\mathrm{d}}{\frac{1}{\mathrm{~N}} \sum T_{i}}$

where $\mathrm{FFS}_{2 \min }$ is the two-minute space mean FFS, $d$ is the section length, $T_{i}$ is the travel time of $i$ th vehicle in a particular two-minute and $N$ is the total number of vehicles entered the segment in the same two minute.

\subsection{Effect of Site Factors on Free-Flow Speed}

The effects of various site-specific factors on FFS were evaluated using graphical and statistical tools. Fig. 2 shows the influence of various site factors (carriageway width, link length, side clearance, landuse, area type, number of access points, road class and presence of kerb) on FFS. It was found that the factors - carriageway width, link length and side clearance - have positive influence of FFS. This is quite intuitive in the sense that any increase in the magnitude of these factors enhances the freedom to manoeuvre and perception of safety. Another important factor that affects the FFS is the type of landuse. In Chennai, there are residential, institutional, commercial and open spaces adjacent to road facilities. Analysis of FFS data shows that the average FFS in residential, commercial, institutional and open areas are $41.03 \mathrm{~km} / \mathrm{h}$, $47.14 \mathrm{~km} / \mathrm{h}, 51.27 \mathrm{~km} / \mathrm{h}$ and $60.13 \mathrm{~km} / \mathrm{h}$, respectively (Fig. $2 \mathrm{~d}$ ). In the case of road class (Fig. 2e), FFS on arterials are found to be higher $(51.98 \mathrm{~km} / \mathrm{h})$ than that on subarterials $(41.58 \mathrm{~km} / \mathrm{h})$. The analysis also reveals that the effect of access points (Fig. 2f) on FFS is rather adverse, probably because they offer greater impedance to free movement of vehicles. Similarly, the mean FFS on urban roads (Fig. $2 \mathrm{~g}$ ) is $47.38 \mathrm{~km} / \mathrm{h}$ while that of suburban roads is higher $(56.24$ $\mathrm{km} / \mathrm{h}$ ). The analysis also indicates that the presence of kerb delineates the roadway from side obstructions, ultimately enhancing FFS (Fig. $2 \mathrm{~h}$ ). The average FFS on roads with FFS is $48.86 \mathrm{~km} / \mathrm{h}$, while that on roads without kerb is $47.96 \mathrm{~km} / \mathrm{h}$, which is slightly lesser.

\section{Free-flow Speed Models}

\subsection{Development of Models}

The analysis of FFS data collected from the selected study segments revealed that FFS is influenced by site factors and vehicle characteristics. However, it is necessary to 
quantify the individual effect of relevant factors on FFS for various applications in planning and operational analysis of urban road facilities. FFS models are developed for this purpose. These models can also be used to predict FFS. In this study, multiple linear regression analysis (MLR) was adopted for modelling FFS.

Table 3

Correlation Matrix

\begin{tabular}{|c|c|c|c|c|c|c|c|c|c|c|c|}
\hline & cway & side & link & lane & subart & suburb & kerb & land.open & land.res & land.com & land.inst \\
\hline cway & 1 & & & & & & & & & & \\
\hline side & 0.11 & 1 & & & & & & & & & \\
\hline link & 0.02 & 0.37 & 1 & & & & & & & & \\
\hline lane & 0.75 & 0.24 & 0 & 1 & & & & & & & \\
\hline subart & -0.45 & -0.22 & -0.14 & -0.34 & 1 & & & & & & \\
\hline suburb & -0.14 & 0.48 & 0.13 & -0.25 & -0.25 & 1 & & & & & \\
\hline kerb & 0.2 & -0.22 & -0.02 & 0.3 & 0.09 & -0.47 & 1 & & & & \\
\hline land.open & -0.12 & 0.78 & 0.19 & -0.2 & -0.18 & 0.49 & -0.34 & 1 & & & \\
\hline land.res & -0.22 & -0.34 & -0.28 & -0.04 & 0.59 & -0.18 & 0.39 & -0.13 & 1 & & \\
\hline land.com & 0.1 & -0.09 & -0.35 & 0.01 & -0.22 & 0.1 & -0.31 & -0.19 & -0.35 & 1 & \\
\hline land.inst & 0.14 & -0.03 & 0.47 & 0.12 & -0.17 & -0.31 & 0.16 & -0.22 & -0.4 & -0.59 & 0.1 \\
\hline
\end{tabular}

Prior to the modelling procedure, it was important to select relevant independent variables from the site factors considered. An important assumption of regression modelling is that the correlation among independent variables must be negligible (multicollinearity). Though this assumption is not perfectly attainable, avoiding highly correlated variables in the model specification is necessary. Linear correlation among independent variables were assessed using Pearson's correlation coefficient $(\rho)$ and frequency tables. Strong correlation was observed between carriageway width and number of lanes, road class and landuse type, and side clearance and landuse type (Table 3 ). This was considered during selection of model specification.

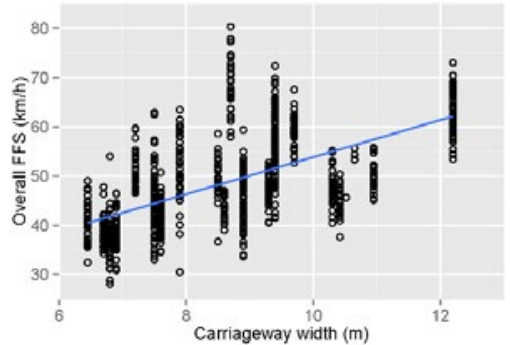

Fig. 2a. Effect of Carriageway Width

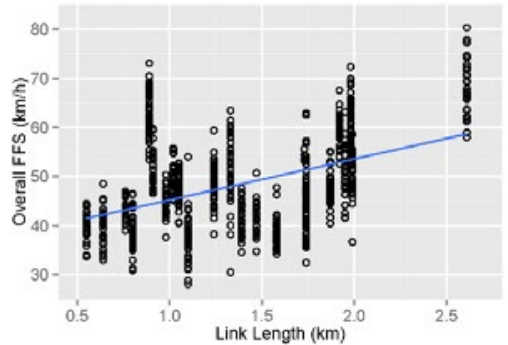

Fig. 2b. Effect of Link Length 


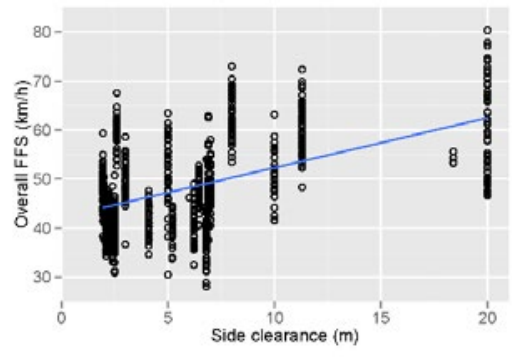

Fig. 2c. Effect of Side Clearance

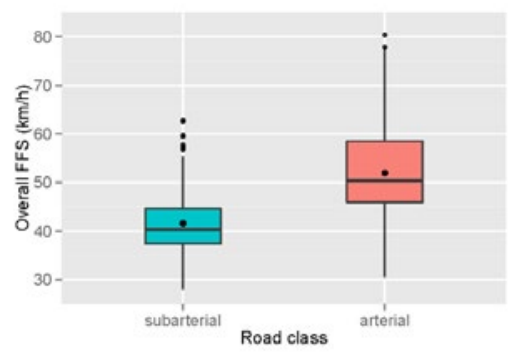

Fig. 2e. Effect of Road Class

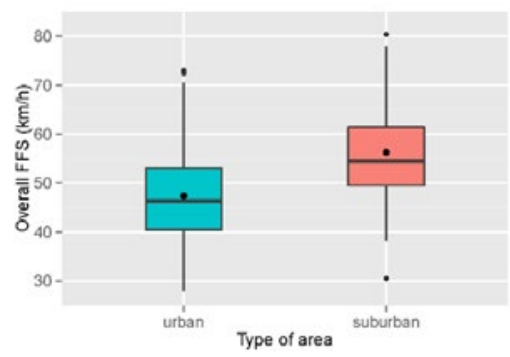

Fig. 2g. Effect of Area Type

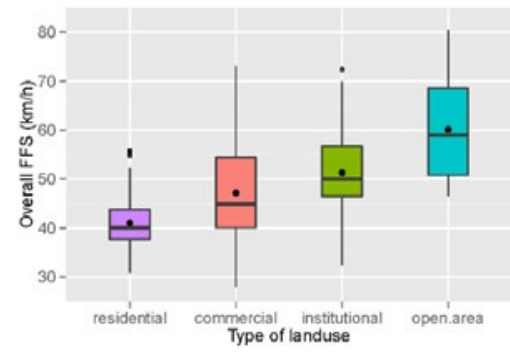

Fig. 2d. Effect of Landuse Type

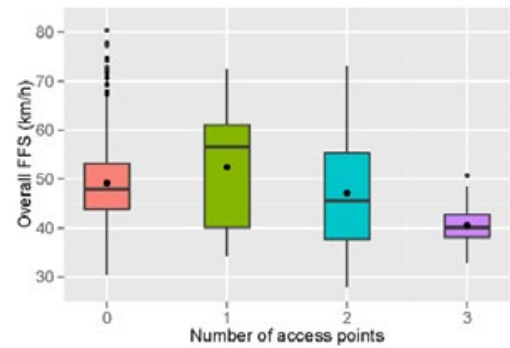

Fig. 2f. Effect of Access Points

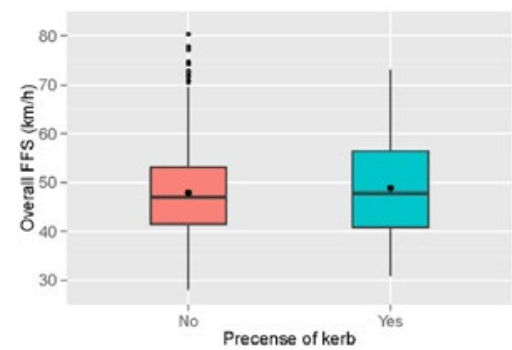

Fig. 2h. Effect of Presence of Kerb

Fig. 2.

Effect of Site Factors Considered in the Study on Free-Flow Speed

For the study, two classes of models were constructed - Base Models (BM) and Classwise Models (CM). The Base Models predict overall FFS on road segments. The Classwise Models consists of separate models for each of the six vehicle classes. The Class-wise models used the same model specification of Base Model. Both Base Models and Class-wise Models were built for divided roads in general as well as for four- and sixlane divided roads, separately. The model specifications were chosen using 'stepwise method' available in the SPSS software (IBM Corp., 2012). 


\subsection{Discussion on FFS Models Developed}

Table 4 through 6 present the outputs of the models developed using regression analysis. The model output discussions are as follows:

\subsubsection{General Models for Divided Roads}

The first set of models were built for predicting overall FFS and class-wise FFS on divided roads in general. These models are applicable for both four- and six-lane divided roads. The model parameters and statistics are presented in Table 4 . The Base Model has a goodness of fit $\left(\mathrm{R}^{2}\right)$ of 0.712 and the Class-wise Models have $\mathrm{R}^{2}$ in the range of 0.21 to 0.61 . All models are found to be statistically significant at $95 \%$ confidence level.

The model specification used in the Base Model consist of carriageway width, link length, type of area, presence of kerb and landuse as independent variables. The model predicts that for every $1 \mathrm{~m}$ increase in width of carriageway, the overall FFS increases by $3.56 \mathrm{~km} / \mathrm{h}$. Similarly, for every $1 \mathrm{~km}$ increase in link length, the FFS increases by $5.01 \mathrm{~km} / \mathrm{h}$. The model consists of three levels of landuse variable - open area, residential area and commercial area - with institutional area as the base level. The model estimates show that the FFS in residential areas and commercial areas are lesser than institutional areas by $4.75 \mathrm{~km} / \mathrm{h}$ and 1.56 $\mathrm{km} / \mathrm{h}$, respectively. However, the free-flow speed in open areas is expected to be 5.21 $\mathrm{km} / \mathrm{h}$ higher than that in institutional areas. The FFS is predicted to be higher by 3.78 $\mathrm{km} / \mathrm{h}$ on roads with kerb compared to roads without kerb, and higher by $8.82 \mathrm{~km} / \mathrm{h}$ on roads in suburban areas compared to those in urban areas. Examining the above model, the parameter estimates of variables including carriageway width and link length indicate that these variables have positive impact on FFS. This is logical, because the increase in magnitude of these variables yield more freedom for manoeuvrability of vehicles. The parameter estimates also support the general presumption that FFS on urban roads are lower than on suburban roads due to higher roadside friction.

The Class-wise Models predict FFS of the corresponding vehicle class, given the details regarding site factors. The primary intention of these models is to assess the variability of effect of site factors on FFS of different vehicle classes under study. The model specification of Class-wise Models is same as that of Base Model. The impact of carriageway width is found to be statistically significant (at $95 \%$ confidence level) and positive across all vehicle classes. Increase in link length positively influence FFS of all vehicle classes, except for trucks. The models suggest that area type is a significant factor influencing FFS of all vehicle classes except for three-wheelers. The model estimates also suggest that FFS of two-wheelers, three-wheelers and LCVs are higher in open areas, compared to the institutional areas. For all the vehicle classes, the categorical level corresponding to commercial areas is statistically insignificant. For all classes of vehicles, the FFS on residential areas are observed to be lower than the institutional areas. The model results also show that the presence of kerb significantly increases the FFS of all classes of vehicles, except for threewheelers.

\subsubsection{Models for Four-Lane Divided Roads}

Table 5. provides the model parameters of the Base and Class-wise Models for four-lane 
divided roads. FFS data from the 15 fourlane roads from the sample were used for developing the models. The models use site factors- carriageway width, link length, area type, landuse type, and presence of kerb as independent variables. The goodness of fit $\left(\mathrm{R}^{2}\right)$ of Base Model is 0.77 , whereas that of Class-wise Models ranges from 0.26 for trucks to 0.66 for cars. All the models are statistically significant at $95 \%$ confidence interval.

The Base Model predicts that for every $1 \mathrm{~m}$ increase in width of carriageway, the overall FFS increases by $4.58 \mathrm{~km} / \mathrm{h}$. Similarly, every $1 \mathrm{~km}$ increase in link length enhances the FFS by $4.77 \mathrm{~km} / \mathrm{h}$. The model estimates show that the FFS in residential areas and commercial areas are lesser than institutional areas by $2.03 \mathrm{~km} / \mathrm{h}$ and 2.68 $\mathrm{km} / \mathrm{h}$ respectively. However, the FFS in open areas, where the road side impedance is nil, is expected to be $5.210 \mathrm{~km} / \mathrm{h}$ more than that of institutional areas. The FFS in suburban areas (where the intensity of roadside activities is lower) is higher than that in urban roads by $8.17 \mathrm{~km} / \mathrm{h}$. The effect of kerb on FFS is found to be negligible on four-lane divided roads.

The Class-wise Models provide the details regarding effect of various side factors on
FFS of individual vehicle classes on four-lane divided roads. For example, the FFS model CM.CAR predicts that FFS of passenger cars increases by $5.58 \mathrm{~km} / \mathrm{h}$ for every $1 \mathrm{~m}$ increase in carriageway width, whereas that for three-wheelers (as predicted by CM.3W) increases by $2.66 \mathrm{~km} / \mathrm{h}$ for every $1 \mathrm{~m}$ increase in carriageway width. Similarly, the effect of landuse on FFS is also dependent on the vehicle classes. For example, the FFS of cars and LCVs in commercial area are lower than that on institutional areas, whereas for other vehicle classes, the difference is statistically insignificant.

\subsubsection{Models for Six-Lane Divided Roads}

Models similar to four-lane roads were developed for six-lane divided roads too (Table 6). FFS data collected from 9 six-lane divided road segments were used for building the models. The model specifications (especially for class-wise models) were modified to avoid multicollinearity and statistical insignificance. The $\mathrm{R}^{2}$ of the Base Model obtained is 0.71. Among the Class-wise Models, the highest $\mathrm{R}^{2}$ is for cars $(0.60)$ and lowest for trucks (0.17). The F-stats show that all models are statistically significant at $95 \%$ confidence level.

\section{Table 4}

General Free-Flow Speed Prediction Models and Coefficients

\begin{tabular}{|l|r|r|r|r|r|r|r|}
\hline \multirow{2}{*}{} & \multicolumn{7}{|c|}{ Coefficient (t-stat) } \\
\cline { 2 - 8 } & BM & CM.2W & CM.3W & CM.CAR & CM.LCV & CM.BUS & CM.TRUCK \\
\hline (Intercept) & $8.51(5.58)$ & $18.92(10.10)$ & $15.72(6.99)$ & $7.60(3.07)$ & $10.09(3.10)$ & $9.06(2.80)$ & $24.15(6.28)$ \\
\hline cway & $3.56(23.98)$ & $2.29(12.54)$ & $2.54(12.08)$ & $4.37(18.15)$ & $3.62(11.85)$ & $3.30(11.38)$ & $2.21(6.33)$ \\
\hline link & $5.01(10.32)$ & $3.50(5.87)$ & $2.24(2.98)$ & $5.81(7.42)$ & $4.25(4.11)$ & $3.36(3.08)$ & $0.21(0.17)$ \\
\hline suburb & $8.82(9.71)$ & $6.05(5.44)$ & $2.32(1.95)$ & $18.46(12.31)$ & $12.21(6.90)$ & $17.97(10.57)$ & $5.44(1.96)$ \\
\hline land.res & $-4.75(-7.04)$ & $-4.45(-5.38)$ & $-4.39(-4.32)$ & $-4.37(-4.01)$ & $-4.63(-3.21)$ & $-6.64(-4.97)$ & $-6.78(-3.23)$ \\
\hline land.com & $-1.56(-2.69)$ & $-0.66(-0.93)$ & $-1.38(-1.72)$ & $-0.57(-0.61)$ & $-1.74(-1.47)$ & $-2.33(-1.94)$ & $-1.82(-1.17)$ \\
\hline land.open & $5.21(4.39)$ & $5.73(3.95)$ & $7.36(3.81)$ & $1.55(0.80)$ & $6.68(2.79)$ & $-4.87(-1.83)$ & $2.00(0.64)$ \\
\hline kerb & $3.78(7.05)$ & $3.07(4.63)$ & $0.33(0.43)$ & $4.79(5.51)$ & $4.76(4.23)$ & $6.03(5.24)$ & $3.69(2.77)$ \\
\hline Summary of Statistics & \multicolumn{7}{|c|}{0} \\
\hline $\mathrm{R}^{2}$ & 0.712 & 0.466 & 0.423 & 0.605 & 0.456 & 0.480 & 0.211 \\
\hline F & 215.651 & 75.395 & 44.764 & 130.864 & 53.172 & 54.374 & 10.421 \\
\hline Sig. of F & 0.000 & 0.000 & 0.000 & 0.000 & 0.000 & 0.000 & 0.000 \\
\hline
\end{tabular}




\section{Table 5}

Four-Lane Free-Flow Speed Prediction Models and Coefficients

\begin{tabular}{|c|c|c|c|c|c|c|c|}
\hline & \multicolumn{7}{|c|}{ Coefficient (t-stat) } \\
\hline & $\mathbf{B M}$ & CM.2W & CM.3W & CM.CAR & CM.LCV & CM.BUS & CM.TRUCK \\
\hline (Intercept) & $3.45(1.48)$ & $16.39(5.55)$ & $12.12(3.22)$ & $2.83(0.69)$ & $4.53(0.84)$ & $-3.19(-0.69)$ & $19.97(3.02)$ \\
\hline cway & $4.58(16.78)$ & $2.85(8.23)$ & $2.66(6.3)$ & $5.58(11.52)$ & $4.92(7.92)$ & $5.10(10.18)$ & $3.10(4.00)$ \\
\hline link & $4.77(8.89)$ & $3.09(4.54)$ & $5.19(5.95)$ & $5.12(5.41)$ & $3.47(3.01)$ & $4.77(3.90)$ & - \\
\hline land.com & $-2.68(-4.03)$ & $-0.75(-0.89)$ & $-0.6(-0.62)$ & $-3.27(-2.76)$ & $-3.64(-2.52)$ & $-1.97(-1.47)$ & $-2.49(-1.42)$ \\
\hline land.open & $3.28(2.94)$ & $5.43(3.84)$ & $8.12(5.16)$ & $-2.75(-1.38)$ & $4.13(1.78)$ & $-4.70(-1.95)$ & $-2.53(-0.72)$ \\
\hline land.res & $-2.03(-2.88)$ & $-1.91(-2.14)$ & $-3.95(-3.31)$ & $-1.29(-1.04)$ & $-2.36(-1.41)$ & $-3.09(-2.26)$ & $-5.92(-2.31)$ \\
\hline suburb & $8.17(9.76)$ & $5.14(4.84)$ & -- & $19.12(12.64)$ & $11.35(7.06)$ & $15.02(10.52)$ & $7.40(2.50)$ \\
\hline kerb & -- & -- & -- & $-1.63(-1.96)$ & -- & -- & - \\
\hline \multicolumn{8}{|c|}{ Summary of Statistics } \\
\hline $\mathrm{R}^{2}$ & 0.776 & 0.527 & 0.469 & 0.664 & 0.572 & 0.616 & 0.264 \\
\hline $\mathrm{F}$ & 236.100 & 75.030 & 51.300 & 131.100 & 64.35 & 144.100 & 12.020 \\
\hline Sig. of F & 0.000 & 0.000 & 0.000 & 0.000 & 0.000 & 0.000 & 0.000 \\
\hline
\end{tabular}

\section{Table 6}

Six-Lane Free-Flow Speed Prediction Models and Coefficients

\begin{tabular}{|l|r|r|r|r|r|r|r|}
\hline & \multicolumn{7}{|c|}{ Coefficient (t-stat) } \\
\cline { 2 - 8 } & BM. & CM.2W & CM.3W & CM.CAR & CM.LCV & CM.BUS & CM.TRUCK \\
\hline (Intercept) & $-17.56(-3.90)$ & $5.73(0.90)$ & $4.73(0.81)$ & $-24.83(-3.51)$ & $-13.28(-1.07)$ & $-23.06(-2.3)$ & $42.77(27.47)$ \\
\hline cway & $5.43(13.87)$ & $3.03(5.47)$ & $3.6(6.17)$ & $6.63(10.83)$ & $4.71(4.54)$ & $5.37(5.91)$ & -- \\
\hline link & $6.02(7.28)$ & $4.42(3.78)$ & -- & $7.56(5.82)$ & $7.78(3.61)$ & $5.47(2.92)$ & -- \\
\hline land.com & $-3.15(-3.44)$ & $-2.49(-1.92)$ & $-3.56(-2.52)$ & $-0.85(-0.59)$ & $-0.38(-0.18)$ & $-4.9(-2.17)$ & -- \\
\hline land.res & $-7.46(-6.15)$ & $-7.31(-4.28)$ & $-5.39(-3.51)$ & $-7.22(-3.80)$ & $-4.24(-1.39)$ & $-5.75(-2.25)$ & -- \\
\hline suburb & $6.59(2.70)$ & $8.23(2.38)$ & -- & $7.81(2.05)$ & -- & -- & -- \\
\hline kerb & $11.36(13.78)$ & $10.10(8.59)$ & $4.98(3.51)$ & $13.31(10.25)$ & $12.71(6.77)$ & $15.95(7.50)$ & $8.48(4.54)$ \\
\hline Summary of Statistics & \multicolumn{7}{|c|}{0} \\
\hline$R^{2}$ & 0.705 & 0.421 & 0.309 & 0.598 & 0.303 & 0.416 & 0.169 \\
\hline F & 78.100 & 23.550 & 14.870 & 48.150 & 13.030 & 20.700 & 20.630 \\
\hline Sig. of F & 0.000 & 0.000 & 0.000 & 0.000 & 0.000 & 0.000 & 0.000 \\
\hline
\end{tabular}

The Base Model, which predicts overall FFS consists of carriageway width, link length, landuse, area type and kerb as influencing variables. As expected, carriageway width and link length positively influences FFS on six-lane divided roads. The FFS in suburban areas is higher than that in urban areas by 6.59 $\mathrm{km} / \mathrm{h}$. Notably, presence of kerb increases FFS on six-lane roads by $11.36 \mathrm{~km} / \mathrm{h}$ compared to roads without kerb. The kerb was found to have very negligible effect on FFS on four-lane divided roads. This pronounced difference in effect of kerb could be due to other factors attributed to six-lane divided roads with kerb. The true effect of kerb could not be, therefore, identified using the present dataset.

The model parameters of Class-wise Models reiterate the influence of vehicle class on
FFS of vehicles. The class-wise models show the effect of site-specific factors is unique for each vehicle class. It is found that the effect of most of the site factors on FFS of trucks is insignificant on six-lane divided roads, pointing towards the unique speeding behaviour of truck drivers.

To sum up, the Base Model specifications consist of only site-specific variables. These models assume that vehicle composition is constant on all divided roads. The models do not capture the effect of variations in vehicle composition. To resolve this limitation, Class-wise Models were also developed. From the Class-wise Models, it is understood that the response of vehicles classes to the site-specific factors are unique for each class and vary significantly across the classes. It 
is important to note that most of the sitespecific features have little influence on the FFS of trucks. Fast moving vehicles such as cars and LCVs, however, are sensitive to most of the site-specific features considered for the study.

\subsubsection{Development of Overall FFS Model from Class-wise Models}

In the present study, the class-wise models are used to estimate the FFS of the six classes of vehicles. The overall FFS can be obtained from the class-wise FFS and corresponding vehicle proportions using the following method (Eq. 2):

$\mathrm{FFS}=(\mathrm{p} 2 \mathrm{~W} \times \mathrm{FFS} .2 \mathrm{~W})+(\mathrm{p} 3 \mathrm{~W} \times \mathrm{FFS} .3 \mathrm{~W})+(\mathrm{pCar} \times \mathrm{FFS} . \mathrm{Car})+$ $+($ pLCV $\times$ FFS.LCV $)+($ pBus $\times$ FFS.Bus $)+($ pTruck $\times$ FFS.Truck $)$

where FFS is the overall FFS; FFS.2W, FFS. $3 W, \ldots$, FFS.Truck are the class-wise FFS in the given study stretch and $p_{2 W}, p_{3 W}, \ldots, p_{\text {Truck }}$ are the class-wise proportions in a particular two-minute. The class-wise proportions are obtained from the vehicle composition data.

The $\mathrm{R}^{2}$ of the combined FFS model for divided roads in Chennai is found to be 0.720 , which is comparable to that of the Base Model (0.712). The combined model, thus, is equally effective in predicting FFS as well as in understanding the interactions between vehicle classes and various road characteristics. In heterogeneous traffic, the vehicle composition may vary spatially and temporally. Hence, it is important to take the effect of vehicle composition into consideration while computing FFS. However, Base Models do not account for the variation in composition. The limitations of Base Models (BM) are, thus, resolved in the combined model.

\subsubsection{Validation Results}

The models were validated to ascertain if these could be used to predict the FFS of an independent sample of vehicles from Chennai. The FFS prediction models were built using $70 \%$ of data collected. The models were validated using the same $70 \%$ data (internal validation). The models were then validated using the rest $30 \%$ data (external validation). The data for model development and validation were selected randomly from the whole sample. The predicted values of FFS were compared with the observed FFS and Mean Absolute Percentage Error (MAPE) was computed (Equation 3). The validation results showed that the MAPE values of Base Models are less than $10 \%$ and that of Class-wise Models are below 20\%.

$M A P E=\frac{100}{n} \sum\left|\frac{y_{\text {observed }}-y_{\text {predicted }}}{y_{\text {observed }}}\right|$

where $y_{\text {observed }}$ is the observed FFS, $y_{\text {predicted }}$ is the predicted FFS and $n$ is the total sample size.

There are other factors such as driver and vehicle performance characteristics which could potentially influence FFS. These factors were not in the scope of this study and hence were not analysed. The assumptions of regression analysis such as autocorrelation, normality and independence of error terms, heteroscedasticity, multicollinearity and presence of outliers were also checked using standard statistical procedures. The developed models satisfied all the aforementioned regression assumptions. 


\section{Conclusions}

The present study estimated the FFS on the selected study sections with widely varying roadway characteristics. The study also evaluated the variability in FFS with respect to different vehicle groups (classes and subclasses), which is considered to be an important aspect in heterogeneous traffic. Site investigations and video data collection were conducted to gather data for the study (site-specific and vehicle specific data). Statistical analysis and modelling methods were applied to study the FFS patterns and their association with various influencing factors under consideration. Overall and class-wise FFS models were developed using multiple linear regression technique for divided roads. The following key findings and conclusions are drawn from the study:

1. Individual FFS are influenced significantly by the class of the vehicle. The class-wise average speeds increased in the following order-three-wheelers $(39.7 \mathrm{~km} / \mathrm{h})$, trucks $(45.9 \mathrm{~km} / \mathrm{h})$, buses $(46.8 \mathrm{~km} / \mathrm{h})$, two-wheelers $(47.5 \mathrm{~km} / \mathrm{h})$, light commercial vehicles $(53.3 \mathrm{~km} / \mathrm{h})$ and passenger cars $(61.3 \mathrm{~km} / \mathrm{h})$. These are based on data from Chennai, India;

2. The FFS also varied across subclasses. Among two-wheelers, motor bikes were found to be fastest and mopeds the slowest. Among light commercial vehicles, the passenger carriers were found to be faster than goods carriers. Intercity buses were much faster than MTC buses and institutional buses. However, the speed differences among subclasses of passenger cars and threewheelers were not considerable;

3. Area type, landuse type, road class, and number of lanes are the site factors significantly influencing FFS;
4. From the Base Models, it is inferred that increase in carriageway width and link length increases FFS. The models indicate higher FFS in suburban areas compared to those in urban areas, on roads with kerb compared to those without, in open and institutional areas compared to those in commercial and residential areas;

5. The Class-wise Models show that the influence of site factors on FFS varies significantly across vehicle classes. It is found that trucks are least influenced by various site factors considered in the study;

6. The combined model developed using class-wise models is more efficient than base models for predicting overall FFS. At the same time, it offers the flexibility to analyze the effect of vehicle composition on FFS, unlike base models. This is a better approach to analyze vehicle free-flow speeds under heterogeneous traffic conditions.

The above conclusions are based on data from Chennai, India and are based on factors considered and limitations of the study. The study is believed to be one of the earliest attempts to study the effect of vehicle composition on FFS under Indian traffic conditions. The developed models can find applications in planning and operational analysis of urban road facilities. The study could be extended to undivided roads, incorporating effect of signalized intersections on FFS, etc. to develop network-wide FFS models.

\section{Acknowledgement}

The support for this work by the Centre of Excellence in Urban Transport at Indian Institute of Technology Madras, India, funded by the Ministry of Urban Development, Government of India, is gratefully acknowledged. 


\section{References}

Anjaneyulu, M.V.L.R.; Nagaraj, B.N. 2009. Modelling congestion on urban roads using speed profile data, Journal of Indian Road Congress 70: 65-74.

Balakrishnan, S.; Sivanandan, R., 2015. Influence of lane and vehicle subclass on free-flow speeds for urban roads in heterogeneous traffic, Transportation Research Procedia 10: 166-175.

Bang, K.L. 1995. Impact of side friction on speed-flow relationships for rural and urban highways. Bandung, Indonesia.

Bang, K.L.; Carlsson, A.; Palgunadi. 1995. Development of speed-flow relationships for Indonesian rural roads using empirical data and simulation, Transportation Research Record 1484: 24-32.

Cambridge Sytematics; Dowling Associates; System Metrics Group; Texas Transportation Institute. 2008. Cost-effective performance measures for travel time delay, variation, and reliability. Washington DC, United States: Transportation Research Board. 69 p.

Dixon, K.; Wu, C.-H; Sarasua, W; Daniel, J. 1999. Posted and free-flow speeds for rural multilane highways in Georgia, Journal of Transportation Engineering 125(6): 487-494.

Fazio, J.; Wiesner, B.N.; Deardoff, M.D. 2014. Estimation of free-flow speed, KSCE Journal of Civil Engineering 18(2): 646-650.

Figueroa, A.M.; Tarko, A.P. 2005. Speed factors on two-lane rural highways in free-flow conditions, Transportation Research Record: Journal of the Transportation Research Board 1912: 39-46.

Himes, S.C.; Donnell, E.T.; Porter, R.J. 2013. Posted speed limit: To include or not to include in operating speed models, Transportation Research Part A: Policy and Practice 52: 23-33.
Kadiyali, L.R.; Viswanathan, E.; Gupta, R.K. 1983. Free speeds of vehicles on Indian roads, Journal of Indian Road Congress 42(3).

Kyte, M.; Khatib, Z; Shannon, P; Kitchener, F. 2000. Effect of environmental factors on free-flow speed. In Fourth International Symposium on Highway Capacity. Maui, Hawaii, 108-119.

De Luca, M.; Lamberti, R.; Dell'Acqua, G. 2012. Freeway free flow speed: A case study in Italy. In 15th Meeting of the EURO Working Group on Transportation. Paris, France, 628-636.

Ma, Y.; Zeng, Y.; Yang, X. 2010. Impact of lane width on vehicle speed of urban arterials. In ICCTP 2010: Integrated Transportation Systems: Green, Intelligent, Reliable. Beijing, China: American Society of Civil Engineers, 1844-1852.

Madhu, E.; Reddy, T.S.; Madhu, S. V. 2004. Updating free speed models through mechanistic principles for Indian conditions, Journal of Advanced Transportation $38(2)$.

Moses, R.; Mtoi, E. 2013. Evaluation offree flow speeds on interrupted flow facilities, Tallahassee, United States. 65 p.

Odoki, J.B.; Kerali, H.G. 2000. Analytical Framework and Model Structure, Volume 4, PAIRC, Paris, France.

Rao, A.M.; Rao, K.R. 2015. Free speed modeling for urban arterials - A case study on Delhi, Periodica Polytechnica Transportation Engineering 43(3): 111-119.

Ross, M. 1994. Automobile fuel consumption and emissions: Effects of vehicle and driving characteristics, Annual Review of Energy and the Environment 19(1): 75112.

Saifizul, A.A.; Yamanaka, H.; Karim, M.R. 2011. Empirical analysis of gross vehicle weight and freeflow speed and consideration on its relation with differential speed limit, Accident Analysis \& Prevention 43(3): 1068-1073.

\section{ijtte ${ }^{59}$}


Schrank, D.; Eisele, B.; Lomax, T. 2012. TTI's 2012

Urban Mobility Report. Texas Transportation Institute, College Station, Texas. 68 p.

Sun, D. 2010. Study of the effectiveness of nighttime and truck speed limits. In Traffic and Transportation Studies 2010. Reston, VA: American Society of Civil Engineers, 977-989.

Transportation Research Board. 2010. Highway Capacity Manual, Washington DC, United States: Transportation Research Board.

Tseng, P.Y.; Lin, F.B.; Shieh, S.L; 2005. Estimation of free-flow speeds for multilane rural and suburban highways, Journal of East Asian Society of Transportation Studies 6: 1484-1495.

Yagar, S.; Van Aerde, M. 1983. Geometric and environmental effects on speeds of two-lane highways, Transportation Research Part A: general 17(4): 315-325.

Yusuf, I.T. 2010. The factors for free-flow speed on urban arterials - Empirical evidences from Nigeria, Journal of American Science 6(12): 1487-1497. 